\title{
ESTUDO DA FREQÜÊNCIA E CARACTERIZAÇÃO GENOTÍPICA E FENOTÍPICA DE AMOSTRAS DE ESCHERICHIA COLI PRODUTORAS DA TOXINA SHIGA (STEC) ISOLADAS DE OVINOS NO ESTADO DE SÃO PAULO
}

Tese apresentada ao Programa de Pós-Graduação
em Microbiologia do Instituto de Ciências
Biomédicas da Universidade de São Paulo, para
obtenção de Título de Doutor em Ciências
Biológicas.

Área de Concentração: Microbiologia

Orientador: Prof. Dr. Antonio Fernando Pestana de Castro

Co-orientadora: Profa. Dra. Beatriz Ernestina Cabilio Guth

São Paulo 


\section{RESUMO}

VETTORATO, M. P. Estudo da frequiência e caracterização genotípica e fenotípica de amostras de Escherichia coli produtoras da Toxina Shiga (STEC) isoladas de ovinos no Estado de São Paulo. 2008. 90 f. Tese (Doutorado em Ciências) - Instituto de Ciências Biomédicas da Universidade de São Paulo, São Paulo, 2008.

O gado ovino tem sido apontado como importante reservatório para amostras de Escherichia coli produtora da toxina Shiga (STEC) em diversos países. No entanto, não há estudos envolvendo STEC em ovinos na América do Sul. O presente estudo foi conduzido com amostras de 100 carneiros, com idades entre três meses e quatro anos, provenientes de diferentes fazendas no Estado de São Paulo. A técnica de PCR foi empregada para a detecção das sequências $s t x_{1}$, stx $x_{2}$, eae e $e h x$, e para a identificação dos subtipos de intiminas. RFLPPCR foi realizado para identificação das variantes de $s t x_{1}$ e $s t x_{2}$ e do gene flagelar fliC em isolados não-móveis $\left(\mathrm{H}^{-}\right)$. A expressão de enterohemolisina (Ehx) e Stx foi examinada através de procedimentos padrões. Apenas cinco isolados $(5 \%)$ foram $e a e^{+} s t x^{-}$, sendo pertencentes aos sorotipos O128:H2 (2), O145:H2, O153:H7 O178:H7, e portadores de intiminas $\beta, \gamma$ e $\varepsilon$. Cinquienta e seis isolados STEC (56\%) foram obtidos dos 100 animais e os genótipos stx identificados foram $s t x_{1 c} s t x_{2 \mathrm{~d}-\mathrm{O} 118}(56,1 \%)$, stx $x_{1 \mathrm{c}}(33,3 \%)$, stx $x_{2 \mathrm{~d}-\mathrm{O} 118}(7,6 \%)$, e $s t x_{1 \mathrm{c}} s t x_{2 \mathrm{dOX} 3 \mathrm{a}}$ (3\%). Uma grande diversidade de sorotipos foi observada entre amostras STEC, e os sorotipos mais freqüentes foram ONT:H8 (13 isolados), ONT: $\mathrm{H}^{-}(9), \mathrm{O}^{-} \mathrm{H}^{-}(7), \mathrm{O} 174: \mathrm{H} 8$ (6) e $\mathrm{O} 5: \mathrm{H}^{-}$ (5). O gene fliC codificando para os tipos flagelares H2, H8, H14, H16, H19, H21 ou H28 foi identificado entre 25 dos 33 isolados não-móveis. Não foi possível estabelecer uma correlação entre sorotipos e genótipos stx. A presença do gene $e h x$ foi detectada em três de cinco isolados $e a e^{+}$e em $38(57,6 \%)$ dos 66 isolados STEC, que por sua vez também expressaram Ehx. Cinqüenta e um de $66(77,2 \%)$ isolados STEC mostrou-se sensível a todos agentes antimicrobianos testados; porém, foi identificada resistência a ampicilina, estreptomicina, tetraciclina e/ou sulfonamida. A análise da similaridade genética realizada por eletroforese em campo pulsado (PFGE) revelou 24 distintos perfis entre 40 isolados de STEC e EPEC atípicas. Isolados de E. coli pertencentes aos sorotipos ONT:H16, ONT:H14, ONT:H8, O128:H2 e O146:H21 apresentaram 100\% de similaridade genética, sugerindo uma distribuição clonal nestes casos. Isolados dos sorotipos O75:H- e O174:H8 demonstraram variações no índice de similaridade genética. Pode-se concluir que importantes dados foram 
obtidos, demonstrando que ovinos saudáveis podem se comportar como reservatórios de STEC e EPEC atípica. Considerando-se que alguns sorotipos identificados neste estudo estão relacionados a casos de SHU em outros países, o papel dos ovinos como fonte de infecção por STEC é de grande relevância.

Palavras-chave: STEC; EPEC Atípica; Ovinos; Fatores de virulência; Sorotipos; PFGE. 


\begin{abstract}
VETTORATO, M. P. A comparative study of Shiga toxin-producing Escherichia coli and Atypical Enteropathogenic Escherichia coli strains isolated from healthy ovine of different populations in São Paulo, Brazil. 2008. 90 p. $\mathrm{PhD}$ Thesis (Doutorado em Ciências) - Instituto de Ciências Biomédicas da Universidade de São Paulo, São Paulo, 2008.
\end{abstract}

Lambs have been reported as carriers of Shiga toxin-producing Escherichia coli (STEC) in several countries. However, there is a paucity of data about ovine STEC in South America. The present research was carried out with 100 healthy sheep, aging three months up to four years old from different farms in São Paulo, Brazil. PCR was used for detection of $s t x_{1}, s t x_{2}$, eae and $e h x$ genes, and for identification of intimin subtypes. RFLP-PCR was performed to investigate the variants of $s t x_{1}$ and $s t x_{2}$, and the flagellar antigen $(f l i C)$ genes in nonmotile $\left(\mathrm{H}^{-}\right)$isolates. Expression of enterohemolysin (Ehx) and Stx was examined by standard procedures. Only five (5\%) isolates were eae+ and stx-. They belonged to serotypes O128:H2 (2), O145:H2, O153:H7 and O178:H7, and carried $\beta, \gamma$ and $\varepsilon$ intimins. Fifty-six $(56 \%)$ isolates of STEC were recovered from the 100 animals, and the stx genotypes identified were $s t x_{1 \mathrm{c}} s t x_{2 \mathrm{~d}-\mathrm{O} 118}(56.1 \%)$, stx $x_{1 \mathrm{c}}(33.3 \%)$, $\operatorname{stx}_{2 \mathrm{~d}-\mathrm{O} 118}(7.6 \%)$, and $s t x_{1 \mathrm{c}} s t x_{2 \mathrm{dOX} 3 \mathrm{a}}(3 \%)$. A wide diversity of serotypes was observed among STEC, but the most frequent serotypes


gene coding for flagellar types $\mathrm{H} 2, \mathrm{H} 8, \mathrm{H} 14, \mathrm{H} 16, \mathrm{H} 19, \mathrm{H} 21$ or H28 was identified in 25 of 33 non-motile isolates. No correlation could be established between serotypes and stx genotypes. The presence of $e h x$ gene was detected in three out of the five eae+ strains, and in $38(57,6 \%)$ of the 66 STEC isolates, that also expressed Ehx. Fifty-one (77.2\%) of the STEC isolates were susceptible to all antimicrobial drugs tested, but resistance to ampicillin, streptomycin, tetracycline and/or sulfonamide was also identified. Pulsed field gel electrophoresis (PFGE) analyzes revealed 24 distinct profiles among 40 STEC and atypical EPEC isolates, and a clonal distribution of some isolates in different farms belonging to serotypes ONT:H16, ONT:H14, ONT:H8, O128:H2 and O146:H21 is suggested, since they presented $100 \%$ of genetic similarity. Serotypes like O75:H- and O174:H8 showed a more diverse distribution in the genetic profile. In conclusion, very important data were obtained, showing that healthy ovine can be carrier of STEC and atypical EPEC in Brazil. As some of 
the STEC serotypes presently found have been involved in cases of HUS in other countries, the role of ovine as sources of STEC infection in our settings should not be disregarded.

Key words: STEC; Atypical EPEC; Sheep; Virulence markers; Serotypes; PFGE. 


\section{INTRODUÇÃO}

Os bacilos gram-negativos que constituem a família das enterobactérias são bactérias isoladas com elevada freqüência em amostras biológicas e apresentam muitas propriedades em comum. Importantes agentes causadores de infecções intestinais compõem esta família, onde se destaca a Escherichia coli (KONEMAN et al., 2001; TRABULSI e ALTERTHUM, 2004).

Amostras de E. coli podem causar grande variedade de doenças, tanto no homem quanto em animais. Dentre essas doenças, as mais comuns são diarréia e disenteria, e ocasionalmente também pode ocorrer síndrome hemolítica urêmica (SHU), colite hemorrágica $(\mathrm{CH})$, pielonefrite, cistite, septicemia, pneumonia e meningite. Em geral, diferentes amostras estão associadas com doenças diversas, podendo apresentar um ou mais fatores ou mecanismos de virulência (SALYERS e WHITT, 1994). A habilidade de E.coli em causar diferentes tipos de doenças é devida à expressão de vários e distintos fatores de virulência, cujos genes responsáveis por sua codificação podem estar localizados no cromossomo, em plasmídios ou fagos (TRABULSI, 1999).

De acordo com suas propriedades de virulência específicas, a presença de determinados sorotipos e sintomatologia apresentada pelo hospedeiro, as E. coli associadas a infecções intestinais são classificadas em seis patótipos: E. coli enteropatogênica (EPEC), E. coli enterotoxigênica (ETEC), E. coli enteroinvasora (EIEC), E. coli enteroagregativa (EAEC), E. coli que adere difusamente (DAEC) e E. coli produtora de toxina de Shiga (STEC) (NATARO e KAPER, 1998).

Dentre as distintas categorias de E. coli diarreiogênicas, as STEC merecem destaque como bactérias emergentes relacionadas com a ingestão de alimentos, uma vez que a doença causada por estas bactérias varia desde uma diarréia branda até severas diarréias sanguinolentas (colites hemorrágicas - $\mathrm{CH}$ ) que podem evoluir para complicações extraintestinais graves como a Síndrome Hemolítica Urêmica (SHU) e a Púrpura Trombocitopênica (PTT), sendo que o grupo de amostras relacionado a estes agravos é denominado de E. coli enterohemorrágica (EHEC) (MORA et al., 2005). As EHEC constituem, portanto, um subgrupo das STEC (JOHNSON et al., 1983; LEVINE et al., 1987; WHIPP et al., 1994).

EHEC é um patógeno intestinal capaz de causar doença em humanos com um número baixo de unidades formadoras de colônias (UFC). Crianças, menores de 10 anos e idosos 
constituem os principais grupos de risco que podem desenvolver SHU (GRIFFIN e TAUXE, 1991). Em aproximadamente 3 a 5\% das crianças afetadas a SHU é fatal, enquanto que 12 a $30 \%$ sofrem comprometimento na função renal ou lesão neurológica (NATARO e KAPER, 1998; PATON e PATON, 1998).

Desde 1982, quando foi identificada como patógeno, a STEC O157:H7 vem sendo apontada como causa de surtos que ocorreram primariamente no Canadá, Japão, Reino Unido e Estados Unidos (MORA et al., 2005).

Em 1977, Konowalchuk et al. descreveram que algumas cepas de E. coli eram capazes de produzir uma toxina, referida como Verotoxina (VT), que induzia um efeito citotóxico distinto e irreversível em células Vero (linhagem celular de rim de macaco verde africano), daí a denominação inicial desta toxina de Verotoxina (VT). No entanto, estudos conduzidos por O'Brien et al. (1982), demonstraram que o efeito citotóxico produzido por estas amostras de E. coli em células de adenocarcinoma de colo uterino humano (células HeLa) podia ser neutralizado através do uso de anti-soro contra toxina de Shigella dysenteriae tipo 1. Desta forma, a toxina VT produzida por este grupo de E. coli passou a ser designada, pela maioria dos autores, de "Shiga-like toxin" (SLT).

Riley et al. (1983) isolaram amostras de E. coli do sorotipo O157:H7 em um surto nos Estados Unidos associado à ingestão de hambúrguer mal cozido que apresentou sintomas como: dores abdominais, diarréia aquosa seguida de diarréia sanguinolenta, febre baixa ou ausente, caracterizando um quadro clínico denominado de colite hemorrágica. As amostras de E. coli isoladas neste surto revelaram a presença de SLT. Em um estudo realizado posteriormente, O'Brien et al. (1983) demonstraram que SLT e a citotoxina Vero eram a mesma toxina. Concluiu-se, então, que a citotoxina Vero e STL eram fatores de virulência comumente encontrados em casos de CH e SHU (KARMALI et al., 1983). A adoção do termo Stx para a toxina Shiga padronizou a sua nomenclatura, embora grupos distintos de pesquisadores ainda designem esta citotoxina como VT (Toxina Verocitotoxigênica) (CALDERWOOD et al., 1996).

Mais de 200 sorotipos de E. coli apresentam a capacidade de produzir Stx, entretanto o sorotipo O157:H7 tem sido considerado o mais importante (NATARO e KAPER, 1998.), por estar associado a surtos de colite hemorrágica já descritos em literatura, e a um significativo número de óbitos, sendo que o maior surto ocorreu no Japão (RILEY et al, 1983; MICHINO et al., 1999; LICENCE et al., 2001). Amostras de STEC isoladas de humanos e de animais que causam infecções em humanos pertencentes a um grande número de sorotipos 
O:H não-O157 (MORA et al., 2005) estão associados a um número estimado de 37 mil mortes por ano (GANSHEROFF et al., 2000).

Apesar de STEC causar diarréia e disenteria em bezerros (MOHAMMAD et al., 1985; MAINIL et al., 1993), esta bactéria é albergada, na sua maioria, por animais saudáveis e assintomáticos, como bovinos adultos, ovinos e caprinos (ZSCHOCK et al., 2000; WANI et al., 2006). Diferentes estudos têm verificado elevadas freqüências de amostras STEC em ovinos (SIDJABAT TAMBUNAM e BENSINK, 1997; FEGAN e DESMARCHELIER, 1999; URDAHL et al., 2001; VETTORATO et al., 2003; MORA et al., 2005; ODGEN et al., 2005).

Entre os animais ruminantes que estão em contato com o homem, o gado ovino vem se tornando um importante alvo para a pesquisa da prevalência de amostras de STEC. Estudos recentes demonstram e confirmam que estes animais excretam altos níveis destas bactérias (OMISAKIN et al., 2003), além de apresentarem também um alto potencial de excretar amostras STEC O157 no ambiente (MORA et al., 2005; ODGEN et al., 2005).

Além de serem isoladas das fezes de ovinos saudáveis (BEUTIN et al., 1993; FEGAN e DESMARCHELIER, 1999; BETTELHEIM et al., 2000; DJORJEVIC et al., 2001), amostras de STEC têm sido isoladas em abatedouros (CHAPMAN et al., 2001; DJORJEVIC et al., 2001), e ainda, sorotipos potencialmente causadores de doenças em humanos têm sido isolados das carcaças destes animais (KUDVA et al., 1997; CHAPMAN et al, 2001). Alimentos derivados de ovinos vem sendo associados a infecções por STEC, e a contaminação da carne durante o abate é a principal rota pela qual os patógenos entram na cadeia alimentar (MENG e DOYLE. 1998; BARLOW et al., 2006).

Estudos recentes envolvendo a pesquisa de STEC em carnes cruas de bovinos e ovinos revelaram uma maior detecção destas bactérias em amostras ovinas, sugerindo que, nestes animais, talvez a contaminação da carne crua com o material fecal durante o processamento seja por algum motivo facilitada (BARLOW et al., 2006).

Portanto, os ovinos podem comportar-se como reservatório para amostras de STEC, e a ingestão de carne contaminada crua ou mal cozida pode representar importante via de transmissão de bactérias para humanos (KOCH et al., 2001). Bastante interessante e curioso foi o relato da transmissão de amostras de STEC através do ar (VARMA et al., 2003) mostrando a possibilidade das infecções por STEC poderem ser enquadradas entre as "airborne infections". O meio ambiente também é uma maneira pela qual novos clones de STEC patogênicos para humanos, como E. coli O157:H7, podem surgir (VERNOZY- 
ROZAND et al., 2004). Essas bactérias podem sobreviver por longos períodos em estrume de gado, assim como em pasto e em sistemas de água. Tais observações têm importantes implicações na disseminação de STEC O157:H7 para a colheita de verduras, pelo contato direto com o adubo ou irrigação com água infectada, ou mesmo na transmissão dessas amostras diretamente para humanos por contato direto com animais ou fezes dos mesmos ou ainda solo contaminado (WANG, 1996; MAULE, 2000). Deste modo, com base nos resultados obtidos por Verozy-Rozand et al. (2004), observou-se a importância de um manuseio apropriado, e a utilização de adubo e decantação da água são imprescindíveis para que a contaminação do ambiente e de alimentos por STEC seja prevenida.

A E. coli $\mathrm{O} 157: \mathrm{H} 7$ não é conhecida por causar infecção em seus hospedeiros naturais, exceto em humanos. Estudo recentes conduzidos por Rashid et al.(2006) consideram que esta discrepância sugere a hipótese de que fatores de virulência específicos de E. coli O157:H7 são diferentemente regulados quando a bactéria está presente em humanos e no trato animal. Interessantemente, este estudo detectou que alguns genes de virulência são expressos de modo diferente de acordo com a espécie hospedeira.

A patogênese das infecções por STEC ocorre em etapas: sobrevivência no ambiente ácido do estômago, adesão à mucosa e colonização do cólon, produção e absorção de Stx e lesão vascular. Essas bactérias são dotadas de um sistema de regulação que lhes permite se adaptar e sobreviver no ambiente ácido do estômago. Este sistema é semelhante ao descrito em Shigella flexneri. Devido a esta capacidade de adaptação, o número de bactérias necessárias para causar infecção é relativamente pequeno, variando entre 100 a 200. Ultrapassada a barreira gástrica, os patógenos sobreviventes atingem o intestino grosso onde aderem à mucosa, proliferam-se e produzem a toxina Stx (SCHMIDT et al., 1993).

Estima-se que amostras de E. coli O157:H7 são responsáveis por causar aproximadamente 73 mil casos de doença e 60 mortes por ano nos Estados Unidos (GANSHEROFF et al., 2000).

As STEC são capazes de elaborar duas potentes citotoxinas codificadas por fagos, denominadas toxinas Shiga 1 e 2 (Stx1 e Stx2). As Stx compõem uma família de citotoxinas produzidas por Shigella dysenteriae tipo 1 e por isolados STEC, porém, também foram descritas em isolados de Enterobacter spp. e Citrobacter freundii (SCHIMIDT et al., 1993). A toxina, que é produzida no cólon intestinal, é transportada via corrente sanguínea onde atinge os rins, e desta forma causa danos às células renais. A ação direta da toxina, juntamente com a produção local de citocinas, obstrui a microvascularização resultando na inflamação 
dos rins, podendo evoluir para SHU, que é caracterizada pela anemia hemolítica, trombocitopenia e insuficiência renal aguda (ANDREOLI et al., 2002).

Os diferentes tipos de Stx podem variar quanto a potencia, provavelmente relacionada com maior ou menor afinidade pelo receptor presente na superfície celular e/ou de acordo com a eficiência nos transportes intra e intercelulares (ACHESON et al., 1998).

Estas toxinas apresentam uma estrutura básica comum a várias toxinas bacterianas de natureza protéica, representada pelo modelo 1A:5B. A subunidade A de aproximadamente 32 $\mathrm{kDa}$, é composta por duas subunidades: A1 $(25 \mathrm{kDa})$, que representa fração ativa da toxina e A2 (4 kDa) que liga a subunidade A às subunidades B, formada, por sua vez, por um conjunto de frações idênticas de $7,7 \mathrm{kDa}$, responsáveis pela ligação da toxina à célula eucariótica (JACEWICZ et al., 1986; TESH e O'BRIEN, 1991).

O mecanismo de ação das citotoxinas da família Stx envolve a inibição da síntese protéica na célula alvo, função que é mediada pela subunidade A1 que apresenta uma atividade de $\mathrm{N}$-glicosilase, acarretando a remoção de um resíduo de adenina da fração $28 \mathrm{~S}$ da subunidade 60S do ribossomo eucariótico, causando alteração no sítio aminoacil ribossomal e conseqüente inibição do processo de tradução (MELTON-CELSA e O’BRIEN, 1998).

A Stx1 é essencialmente idêntica a citotoxina produzida pela Shigella dysenteriae tipo 1 (Stx), e a Stx2 é antigenicamente distinta desta toxina. Entretanto, tanto Stx1 como Stx2 apresentam a mesma estrutura e atividade de Stx (PATON e PATON, 1998). A similaridade genética entre $s t x_{1}$ e $s t x_{2}$ é de aproximadamente $55 \%$, sendo facilmente distinguíveis imunológica e geneticamente (O’BRIEN et al., 1992).

Estudos em íleo de coelho demonstraram que a Stx parece agir diretamente no ápice das vilosidades estruturais da célula epitelial com maior número de $\mathrm{Gb3}$, tornando essas células mais susceptíveis a inibição da síntese protéica induzida pela toxina (KEENAN et al., 1986; KANDEL et al., 1989).

A toxina não tem efeito na secreção de ânions, atua diminuindo a absorção basal ativa de $\mathrm{NaCl}$, que por sua vez sugere que a indução de acúmulo de fluído seja devida à morte seletiva das células absortivas das vilosidades, diminuindo a absorção intestinal e secreção de fluídos. Desta forma, estas mudanças acabam desregulando o balanço da absorção, favorecendo assim, a secreção de líquidos (CHARNEY et al., 1976).

A capacidade de amostras STEC causar doenças com diferentes graus de severidade tem sido relacionada ao tipo da toxina e também à variante da toxina de Shiga produzida pela 
bactéria. Em um estudo realizado por Cornu et al.(1999), foi observado que pacientes infectados por amostras produtoras de Stx2 desenvolveram SHU com uma freqüência maior do que aqueles cujas amostras produziam apenas Stx1.

A Stx 1 compreende um grupo homólogo com poucas variantes descritas (PATON et al., 1993; PATON et al., 1995). A variante $s t x_{10 \times 3}$ foi primeiramente associada a amostras STEC isoladas de ovinos em um estudo conduzido por Koch et al. (2001), e posteriormente foi renomeada como stx $x_{1 \mathrm{c}}$ por Zhang et al. (2002). A seqüência stx $x_{1}$ derivada de amostras STEC O111:H- e O48:H21, e dos bacteriófagos H19B, 933J e H30 são similares a seqüência derivada de $S$. dysenteriae e resulta em um número limitado de substituições de aminoácidos. Já $s t x_{1 c}$ apresenta 43 diferenças no nucleotídeo quando comparada a stx $x_{1933-J}$, resultando na alteração de 12 aminoácidos (BRETT et al., 2003).

A Stx2 é considerada um importante fator de virulência associado com infecções em humanos (BOERLIN et al., 1999), e diferenças no grau de patogenicidade de certos sorotipos de amostras STEC têm sido relacionadas com variações no subtipo de Stx2 (LINDGREN et al., 1993; MELTON-CELSA et al., 1996). Stx2 constitui um grupo mais amplo de variantes, com até 10 variantes já descritas, onde estão incluídas Stx2c, Stx2d, Stx2e, Stx2f e Stx2g (TYLER et al., 1991; GANNON et al., 1992; PIÉRARD et al., 1998; SCHIMIDT et al., 2000; LEUNG et al., 2003). Estudos sugerem que a seqüência $s t x_{2 c}$ está mais freqüentemente associada a casos de SHU, ao passo que stx $x_{2 \mathrm{~d}}$ apresenta menor patogenicidade, estando relacionada a casos de diarréias (FRIEDRICH et al., 2002). Alguns subtipos de stx ocorrem com maior frequiência em animais do que em humanos (BRETT et al., 2003). Ramachandran et al. (2001) demonstraram que stx $x_{2 \mathrm{~d}}$ está associada com amostras STEC de ovinos, e que em relação a humanos, este subtipo mostrou-se menos tóxico que stx $x_{2}$ e stx $x_{2 c}$ (PIERARD et al., 1998), não estando presente em amostras isoladas de fezes de pacientes com CH e SHU (EKLUND et al., 2002).

Além da produção de Stx, amostras STEC podem expressar uma proteína denominada intimina, responsável pela formação de lesões attaching and effacing (A/E) em células do epitélio intestinal. A intimina é uma proteína de membrana externa de $94 \mathrm{kDa}$, codificada pelo gene cromossomal eae, que por sua vez faz parte de uma ilha de patogenicidade de $35 \mathrm{~kb}$, conhecida como LEE (Locus of Enterocyte Effacement) (Mc DANIEL, et al., 1995; KAPER et al., 1998). Diarréia severa (especialmente $\mathrm{CH}$ ) e SHU estão intimamente associados com amostras que albergam o gene eae (KARMALI, 1989; KHACHATRYAN et al., 2004). 
A atividade de ligação da intimina está localizada na região variável C-terminal com 280 aminoácidos. A comparação da seqüência de aminoácidos de diferentes intiminas revela que as regiões $\mathrm{N}$-terminais são altamente conservadas enquanto as regiões $\mathrm{C}$-terminais demonstram menor similaridade (PHILLIPS e FRANKEL, 2000).

A porção C-terminal da intimina é responsável por sua ligação à célula-alvo, sugerindo que diferentes intiminas são responsáveis por diferentes tropismos na célula hospedeira. Visto que a intimina é altamente imunogênica, acredita-se que essa diversidade dentro do domínio do polipeptídio de ligação à célula seja comandada por seleção natural (PHILLIPS e FRANKEL, 2000).

Devido ao fato do gene eae apresentar uma região $5^{\prime}$ conservada, e outra região 3' heterogênea, o desenvolvimento de primers alelo-específicos tornou possível a diferenciação entre os subtipos de intiminas através da técnica da reação em cadeia da polimerase (PCR). Através de estudos da variação antigênica no domínio de ligação da intimina à célula hospedeira, em 1998, Adu-Bobie et al. identificaram e caracterizaram quatro tipos de intiminas: alpha $(\alpha)$, beta $(\beta)$, gamma $(\gamma)$ e delta $(\delta)$. Desde então, novos subtipos passaram a ser estudados e identificados, como a intimina epsilon ( $\varepsilon$ ) (OSWALD et al., 2000), theta $(\theta)$

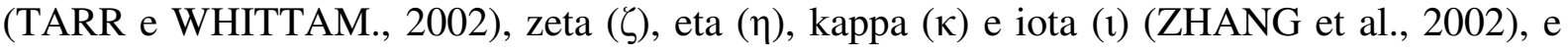
ainda as intiminas micro $(\mu)$, nu (v) e xi ( $\xi$ ) (RAMACHANDRAN et al., 2003). Um estudo conduzido por Zhang et al. (2002), revelou que as intiminas $\gamma$ e $\theta$ são quase idênticas, uma vez que as seqüências apresentam 99,2\% de identidade; considerando, assim, a intimina $\theta$ como sendo um subgrupo da $\gamma$.

Entre ovinos, os subtipos de intiminas mais comumente encontrados são: $\beta, \gamma, \varepsilon$ e $\zeta$ (BLANCO et al., 2003; RAMACHANDRAN et al., 2003).

As variações no tipo de intimina e no seu receptor (a proteína Tir) podem atuar como uma estratégia da própria bactéria para evadir do sistema imune do hospedeiro (PATON et al., 1998).

Como nas EPEC, a habilidade das amostras STEC em causar lesões A/E está associada ao LEE (WIELER et al., 1998). Contudo, alguns estudos demonstraram que o LEE não é essencial para a patogênese de amostras STEC, uma vez que existem relatos de casos de doenças associadas a STEC, incluindo casos de SHU, causados por amostras LEE negativas (KLEANTHOUS et al., 1990; PATON et al., 1999).

A lesão A/E se caracteriza por causar modificações no epitélio intestinal através da destruição das microvilosidades e acúmulo de actina polimerizada além de outros elementos 
do citoesqueleto, levando a formação de estruturas que se assemelham a pedestais (DONNENBERG et al., 1997). Esta lesão foi originalmente identificada entre as EPEC, mas também tem sido confirmada entre amostras STEC (KAPER et al., 1998).

Poucos estudos até o momento relataram a ocorrência de lesões A/E entre amostras isoladas de ovinos. Recentemente, um estudo realizado por Wales et al. (2005) relatou a ocorrência destas lesões de forma espontânea e natural em ovinos assintomáticos, que foram observadas durante estudos experimentais, e não implicam em nenhum efeito clinico na mucosa intestinal destes animais.

As STEC também podem albergar o gene ehxA que está contido em um plasmídio de $90 \mathrm{~kb}$, que codifica uma hemolisina pertencente à família das RTX (toxina com repetições), denominada enterohemolisina de EHEC (Ehx), responsável pela formação de poros (SCHIMIDT et al., 1994; ASAKURA et al., 1998; BOERLIN et al., 1999; FEGAN e DESMARCHELIER, 1999). Grande número de amostras STEC que possuem este genótipo são capazes de expressar o fenótipo hemolítico, que se caracteriza pelo aparecimento de zonas turvas de hemólise ao redor do crescimento bacteriano quando cultivados em meio sólido preparado com eritrócitos lavados (BEUTIN et al., 1988). Entre amostras STEC de ovinos, este fator de virulência ocorre com maior frequiência do que em relação ao gene eae. A prevalência de amostras STEC $e a e^{+}$em ovinos é relativamente baixa, conforme relatado por diversos autores (DJORJEVIC et al., 2001; RAMACHANDRAN et al., 2001).

Paton et al. (2001) descreveram uma nova adesina autoaglutinante denominada Saa (“STEC autoaglutinante adhesin"), cujo gene ( $s a a)$ foi identificado no megaplasmidio de uma amostra do sorotipo O113:H21, responsável por um surto de SHU. Estes autores sugeriram que o gene saa se encontra no mesmo megaplasmideo que codifica genes de enterohemolisina de STEC. O gene saa também foi detectado em outros isolados humanos, incluindo amostras isoladas de surtos esporádicos de SHU. Em 2003, Jenkins et al. também descreveram uma importante associação do gene saa em amostras STEC isoladas de bovinos, sugerindo que a adesina Saa pode ter uma função na ligação da bactéria às células epiteliais do intestino bovino. Recentemente, um estudo realizado por Orden et al. (2005) revelou que, em contraste com amostras STEC eae-negativas de bovinos, nenhum dos isolados de ovinos eram positivos; sugerindo que o gene saa pode estar associado apenas com amostras eae-negativas de bovinos. Em relação às amostras de STEC de ovinos, não existem relatos ainda sobre a presença deste gene. 
Apesar do sorotipo 0157:H7 ser o mais comumente envolvido em surtos em países como Canadá, Estados Unidos, e Reino Unido, entre ovinos, os sorotipos mais freqüentemente encontrados são O5:H, O75:H-, O91:H-, O128:H2, e O146:H21 e ONT:H(KUDVA et al., 1997; BEUTIN et al., 1997; BETTELHEIM et al., 2000; DJODJERVIC et al., 2001; VETTORATO et al., 2003). Ainda, casos graves de infecções em humanos têm sido relacionados a estes sorotipos (GOLDWATER et al, 1995; RUSSMANN et al., 1995; ACHESON et al., 1996); porém, ocorrem de forma esporádica. Os surtos envolvendo amostras STEC, em sua maioria, são reportados e relacionados com o gado bovino (COWDEN et al., 2001) e ovino (LICENCE et al., 2001; STRACHAN et al., 2001).

Em relação ao tratamento de infecções causadas por STEC, sabe-se que o efeito dos agentes antimicrobianos exerce uma influência no curso natural da infecção. Isso devido ao fato de que estes agentes lisam as paredes celulares bacterianas, levando à liberação de Stx (WONG et al., 2000), e/ou causando um aumento na expressão destas toxinas "in vivo" (ZHANG et al., 2000). Desta forma, não é recomendado o uso de antimicrobianos no tratamento de infecções causadas por STEC O157:H7.

No entanto, estudos recentes conduzidos no Japão sugerem que o uso de alguns antibióticos, se administrados no início do curso da infecção, podem prevenir o desenvolvimento de SHU (IKEDA et al., 1999). Ainda assim, o tratamento antimicrobiano em casos de infecções por STEC é considerado controverso (YOU e HONDA, 1997; IGARASHI et al., 1999).

Apesar de infecções causadas por STEC não serem freqüentemente tratadas através de terapia antimicrobiana, e grande parte dos isolados serem susceptíveis a diversos antibióticos, estudos realizados recentemente indicam um crescimento na resistência de STEC em relação a estes agentes (GALLAND et al., 2001; SCHROEDER et al., 2002; MORA et al., 2005; YOU et al., 2005) o que se reflete como uma grave preocupação no mundo todo.

Genes de resistência aos antimicrobianos podem localizar-se no cromossomo bacteriano em plasmídios, e desta forma serem transferidos a outras amostras ou espécies (JAIN e CHAIN, 2006).

Assim, é importante conhecer o perfil de susceptibilidade a agentes antimicrobianos em STEC isoladas de ovinos, uma vez que agentes antimicrobianos vêm sendo rotineiramente utilizado na medicina veterinária, com intuito de prevenir doenças, aumentar a produção, e como fatores de crescimento para os animais. Além disso, existem evidências de que o uso de antibióticos na agricultura contribui fortemente para a ocorrência de resistência a antimicrobianos entre bactérias patogênicas, seja por processo aleatório e/ou seletivo, 
(BETTELHEIM et al., 2003, JAIN e CHAIN, 2006). Esta prática, por sua vez, proporciona a seleção de bactérias resistentes ao antibiótico em questão, fato que ocorre também entre os comensais do trato intestinal de animais que são consumidos por humanos. Desta forma, estes animais passam a ser uma preocupação para a saúde pública, uma vez que se tratados com sub-doses de antimicrobianos podem atuar como reservatórios para cepas resistentes, podendo distribuí-las entre a população humana, e conseqüentemente passam a limitar a eficácia de algumas classes de antimicrobianos (JAIN e CHAIN, 2006).

O desenvolvimento de vacinas contra STEC é um importante alvo a ser explorado dentre estudos envolvendo estas bactérias. De acordo com Toma et al. (2004), a imunização com antígenos que promovem a colonização atuaria como um fator preventivo de efeitos patológicos manifestados na infecção.Vacinas prreparadas como adesinas para o bloqueio da colonização em humanos e em animais poderiam representar um controle eficiente de infecções causadas por STEC, uma vez que a adesão é o primeiro passo na patogênese.

A pesquisa das propriedades adesivas de E. coli diarreiogênicas às células HEp-2 (carcinoma de laringe humana - ATCC CCL - 23) consiste em um método fenotípico, para se caracterizar o perfil de aderência destas bactérias. Este ensaio foi primeiramente descrito por Cravioto et al. (1979) e modificado várias vezes, desde então. Amostras patogênicas de E. coli podem exibir os seguintes padrões de aderência em células epiteliais: Aderência Localizada (AL), Aderência Difusa (AD) e Aderência Agregativa (AA), Aderência Localizada-like (ALL) e Aderência não-característica (NC).

A AL caracteriza-se por microcolônias que aderem em uma ou mais áreas na superfície das células; na $\mathrm{AD}$ as bactérias cobrem de maneira uniforme a célula; e a AA exibe uma forma característica de adesão semelhante a uma parede de tijolos empilhados na superfície das células quando observadas ao microscópio óptico (SCALETSKY et al., 1999). Um novo padrão de aderência foi descrito por Scaletsky et al. (1996) denominado de Aderência Localizada Like (ALL), o qual se caracteriza pela presença de microcolônias menos compactas e grupos de bactérias em poucas células. Em 1998, Gomes et al., descreveram o tipo de aderência Cover Slip (CS), considerado como uma variante da aderência AA.

EPEC compreendem amostras de E. coli diarreiogênicas que produzem uma histopatologia característica conhecida como $\mathrm{A} / \mathrm{E}$ em células intestinais e que não produzem Stx. EPEC típicas de origem humana possuem um plasmídio de virulência conhecido como EAF ("EPEC adherence factor"), que codifica aderência localizada em cultura de células epiteliais mediada por "bundle-forming pili" (BFP), enquanto EPEC atípicas não possuem 
este plasmídio. EPEC típicas e atípicas também deferem entre si quanto ao padrão de adesão. As EPEC típicas apresentam um padrão de adesão característico em ensaios de 3 horas de infecção, denominado de AL (SCALETSKY et al., 1984). Já as EPEC atípicas podem apresentar fenótipos de adesão ALL, AA, AD, bem como variações do padrão de Aderência Localizada (AL) (VIEIRA et al., 2001; TRABULSI et al., 2002).

Dentre os métodos genotípicos, várias técnicas moleculares são atualmente empregadas para a análise genética de microrganismos, muitas das quais tendo por base o estudo do grau de similaridade e relação genética de diferentes amostras, através da análise do DNA genômico. Diferentes métodos têm sido utilizados para caracterizar geneticamente as bactérias. As técnicas mais comuns são: "Restriction Fragment Lenght Polymorphism" (RFLP) (KARAOLIS et al., 1994; LIU et al., 1995), eletroforese em gel de campo pulsado (PFGE) (BRIAN et al., 1993), ribotipagem, e técnicas baseadas no teste PCR (Polymerase Chain Reaction), utilizando iniciadores aleatórios ou de seqüência repetitivas (ARBEIT et al., 1990). Este último apresenta grande importância na discriminação de isolados pertencentes a um mesmo sorotipo.

Essas técnicas moleculares têm complementado metodologias baseadas em descrições fenotípicas, tais como, biotipagem, fagotipagem, perfil de resistência a antimicrobianos e sorotipagem (RODRIGUES et al.,1996).

Estudos demonstram que o PFGE tem se mostrado extremamente importante do ponto de vista epidemiológico na análise de diferentes amostras de O157, e ainda, a associação do PFGE e caracterização genotípica para stx tem revelado ser de grande valia para tipagem epidemiológica de amostras pertencentes a este sorogrupo (WILLSHAW et al., 1997; LOUIE et al., 1999; PRESTON et al., 2000).

Embora ovinos representem um importante reservatório de amostras STEC em diferentes paises, no Brasil, ate o início de nossos estudos, estes dados eram inexistentes. 


\section{CONCLUSÕES}

$>$ Uma elevada freqüência de STEC foi identificada entre amostras obtidas de fezes de ovinos saudáveis em fazendas do estado de São Paulo e uma considerável diversidade de genótipos de STEC foi observada. Todos os isolados STEC foram eae ,e ehx foi identificado em grande parte dos isolados, assim como a presença do gene saa, sendo que uma alta correlação deste último foi observada com $e h x$.

O gado ovino, embora em pequena porcentagem, foi identificado também como portador de EPEC atípica. Os sorotipos pertencentes a estas amostras já foram relatados como causa de doenças em humanos, e apesar de três subtipos de intimina terem sido identificados, o subtipo $\beta$ foi o mais prevalente;

Testes fenotípicos revelaram uma grande diversidade de sorotipos STEC, alguns comumente observados em mais de uma localidade; enquanto outros estiveram restritos a uma única fazenda. A maioria das amostras de E. coli isoladas de ovinos foi sensível aos antimicrobianos testados; entretanto, uma maior freqüência de resistência foi associada à Estreptomicina. As amostras de E. coli apresentaram padrões de aderência característicos em sua maioria, sendo AA e AD as mais prevalentes.

A análise por PFGE revelou uma diversidade de perfis, entretanto a disseminação de clones específicos em animais de uma mesma fazenda ou de localidades distintas pode ser observada;

Este estudo é inédito no Brasil, constituindo-se no primeiro relato abrangente de ovinos como portadores de STEC e EPEC atipícas na América do Sul, e nossos resultados confirmam o gado ovino como um potencial reservatório para amostras STEC. 


\section{REFERÊNCIAS BIBLIOGRÁFICAS*}

ACHESON, D.W.K.; KEUSCH, G.T. Which Shiga toxin-producing types of E. coli are important? ASM News, v. 62, p. 302-306, 1996.

ACHESON, D.W.K.; LINCICOME, L.L.; JACEWICZ, M.S.; KEUSCH, G.T. Shiga toxin interaction with intestinal epithelial cells In: KAPER, J.B.; O'BRIEN, A.D. (Ed.). Escherichia coli O157:H7 and other Shiga toxin-producing $E$. coli strains. Washington, D.C.: ASM Press, 1998. p.140-147.

ADU-BOBIE, J.; FRANKEL, G.; BAIN, C.; GONÇALVES, A. G.; TRABULSI, L.R.T.; DOUCE, G.; KNUTTON, S.; DOUGAN, G. Detection of intimins alpha, beta, gamma, and delta, four intimin derivatives expressed by attaching and effacing microbial pathogens. J. Clin. Microbiol., v. 36, p. 662-668, 1998.

ANDREOLI, S.P. Acute renal failure. Curr. Opin. Pediatr., v.14, p. 183-188, 2002.

ARBEIT, R.D.; ARTHUR, M.; DUNN, R.; KIM, C.; SELANDER, R.K.; GOLDSTEIN, R. Resolution of recent evolutionary divergence among Escherichia coli from related lineages; the application of pulsed field electrophoresis to molecular epidemiology. J. Infect. Dis., v.161, p. 230-235, 1990.

ASAKURA, H.; MAKINO, S.; SHIRAHATA, T.; TSUKAMOTO, T.; KURASONO, H.; IKEDA, T.; TAKESHI, K. Detection and long-term existence of Shiga Toxin (Stx)-producing Escherichia coli in sheep. Microbiol. Immunol., v. 42, p. 683-688, 1998.

BARLOW, R.S.; GOBIUS, K.S.; DESMARCHELIER, P.M. Shiga toxin-producing Escherichia coli in ground beef and lamb cuts: Results of a one-year study. Int. J. Food. Microbiol. v.1, p.1- 5, 2006.

BETTELHEIM, K.A.; BENSINK, J.C.; TAMBUNAM, H.S. Serotypes of Verocytotoxinproducing (Shiga toxin-producing) Escherichia coli isolated from healthy sheep. Comp. Immunol. Microbiol. Infect. Dis. v. 23, p. 1-7, 2000.

BETTELHEIM, K.A.; HORNITZKY, M.A.; DJORDJEVIC, S.P.; KUZEVSKI, A. Antibiotic resistance among verotoxigenic Escherichia coli (VTEC) and non- VTEC isolated from domestic animals and humans. J. Med. Microbiol. v. 52, p. 155-162, 2003.

BEUTIN, L.; PRADA, J.; ZIMMERMANN, S.; STEPHAN R.; ØRSKOV, I.; ØRSKOV, F. Enterohemolysin, a new type of hemolysin produced by some strains of enteropathogenic $E$.

\footnotetext{
* De acordo com:

ASSOCIAÇÃO BRASILEIRA DE NORMAS TÉCNICAS. NBR 6023: Informação e documentação: referências: elaboração. Rio de Janeiro, 2002.
} 
coli (EPEC). Zentralbl. Bakteriol. Mikrobiol. Hyg. Ser. A., v. 267, p. 576-588, 1988.

BEUTIN, L.; MONTENEGRO, M. A.; ØRSKOV, I.; ØRSKOV, F.; PRADA, J.; ZIMMERMANN, S.; STEPHAN R. Close association of Verotoxin (Shiga-like toxin) production with enterohemolysin production in strains of Escherichia coli. J. Clin. Microbiol., v. 27, p. 2559-2564, 1989.

BEUTIN, L; GEIER, D.; ZIMMERMANN, S; KARCH, H. Virulence markers of Shiga-like Toxin-producing Escherichia coli strains originating from healthy domestic animals of different species. J. Clin. Microbiol. v. 33, p. 631-635, 1995.

BEUTIN, L; GEIER, D.; ZIMMERMANN, S.; ALEKSIC, S.; GILLESPIE, H.A.; WHITTAM, T.S. Epidemiological relatedness and clonal types of natural populations of Escherichia coli strains producing Shiga toxins in separate populations of cattle and sheep. Appl. Environ. Microbiol., v. 63, p. 2175-2180, 1997.

BEUTIN, L.; MULLER, W. Cattle and verotoxigenic Escherichia coli (VTEC), an old relationship? Vet. Rec. v. 148, p. 283-284, 1998.

BEUTIN, L.; MARCHES, O.; BETTELHEIM, K.A.; GLEIER, K.; ZIMMERMANN, S.; SCHMIDT, H.; OSWALD, E. HEp-2 cell adherence, actin aggregation, and intimin types of attaching and effacing Escherichia coli strains isolated from healthy infants in Germany and Australia. Infect. Immun., v. 71, p. 3995-4002, 2003.

BEUTIN, L.; KRAUSE, G.; ZIMMERMANN, S.; KAULFUSS, S.; GLEIER, K. Characteristics of Shiga toxin-producing Escherichia coli strains isolated from human patients in Germany over a 3-year period. J. Clin. Microbiol., v. 42, p. 1099-1108, 2004.

BLANCO, M.; BLANCO, J. E.; MORA, A.; REY, J.; ALONSO, J. M.; HERMOSO, M.; ALONSO, M. P.; DAHBI, G.; GONZÁLEZ, E. A.; BERNÁRDEZ, M. I.; BLANCO, J. Serotypes, virulence genes and intimin types of Shiga toxin (Verotoxin)-producing Escherichia coli isolates from healthy sheep in Spain. J. Clin. Microbiol., v. 41, p. 13511356, 2003.

BOERLIN, P.; MC EWEN, S.A.; BOERLIN-PETZOLD, F.; WILSON, J.B.; JOHNSON, R.P.; GYLES, C.L. Association between virulence factors of Shiga toxin-producing Escherichia coli and disease in humans. J. Clin. Microbiol., v. 37, p. 497-503,1999.

BRETT, K.N.; RAMACHANDRAN, V.; HORNITZKY, M.A.; BETTELHEIM, K.A.; WALKER, M.J.; DJORDJEVIC, S.P. stx $x_{1 \mathrm{c}}$ is the most common Shiga toxin 1 subtype among Shiga toxin-producing Escherichia coli isolated from sheep but not among isolated from cattle. J. Clin. Microbiol., v. 41, p. 926-936, 2003.

BRIAN, M.J., VAN. R.; TOWNSEND, I.; MURRAY, B.E.; CLEARY, T.G.; PICKERING, L.K. Evaluation of the molecular epidemiology of an outbreak of multiply resistant Shigella 
sonnei in a day-care center by using pulsed-field gel electrophoresis and plasmid DNA analysis. J. Clin. Microbiol., v. 8., p.2152-2156, 1993.

CALDERWOOD, S.B.; ACHESON, D.W.K.; KEUCSH, G.T.; BARRETT, T.J.; GRIFFIN, P.M.; STROCKBINE, N.A.; SWAMINATHAN, B.; KAPER, J.B.; LEVINE, M.M.; KAPLAN, B.S.; KARCH, H.; O'BRIEN, A.D.; OBRIG, T.G.; TAKEDA, Y.; TARR, P.I.; WACHSMUTH, I.K. Proposed new nomenclature for Shiga like toxin (verotoxin) family. ASM News. v. 62, p.118-119, 1996.

CARVALHO, V.M.; GYLES, C.L.; ZIEBELL, K.; RIBEIRO, M.A.; CATÃO-DIAS, J.L; SINHORINI, I.L.; OTMAN, J.; KELLER, R.; TRABULSI, L.R.; CASTRO, A.F.P. Characterization of monkey Enteropathogenic Escherichia coli (EPEC) and human typical and atypical EPEC serotypes isolates from neotropical nonhuman primates. J. Clin. Microbiol. v. 41, p. 1225-1234, 2003.

CERGOLE-NOVELLA, M.C., L.S. NISHIMURA, K. IRINO, T.M.I. VAZ, A.F.P. DE CASTRO, L. LEOMIL, B.E.C. GUTH. stx genotypes and antimicrobial resistance profiles of Shiga toxin-producing Escherichia coli strains isolated from human infections, cattle and foods in Brazil. FEMS Microbiol. Lett., v. 259, p. 234-239. 2006.

CLINICAL LABORATORY STANDARD INSTITUTE. Performance Standards for Antimicrobial Susceptibility Testing. (M100-S17). 17 $7^{\text {th }}$ edn. Wayne, Pa: CLSI, 2007.

CHAPMAN, P.A.; CERDÁN MALO, A.T.; ELLIN, M.; ASHTON, R.; HARKIN, M.A. Escherichia coli $\mathrm{O} 157$ in cattle and sheep at slaughter, on beef and lamb carcasses and in raw beef and lamb products in South Yorkshire, UK. Intern. J. Food Microbiol., v. 64, p. 139150 .

CHARNEY, A.N.; GOTS, R.E.; FORMAL,S.B.; GIANNELLA, R.A. Activation of intestinal mucosal adenylate cyclase by Shigella dysenteriae I enterotoxin. Gastroenterology, v. 70, p. 1085-1090, 1976.

CORNU, G.; PROESMANS, W.; DEDISTE, A.; JACOBS, F.; VAN DE WALLE, J.; MERTENS, A.; RAMEL, J.; LAWERS, S. Hemolitic uremia síndrome in Belgium: incidence and association with verocytotoxin-producing Escherichia coli infection. Clin. Microbiol. Infect., v. 5, p. 16-22, 1999.

COWDEN, J.M.; AHMED, S.; MDONAGHY, M.; RILEY, A. Epidemiological investigation of the Central Scotland outbreak Escherichia coli O157 infection, November to December, 1996. Epidemiol. Infect., v. 126, p. 335-341, 2001.

CRAVIOTO, A.; GROSS, R.J.; SCOTLAND, S.M.; ROWE, B. An adhesive factor found in strains of Escherichia coli belonging to the traditional infantile enteropathogenic serotype. Curr. Microbiol., v. 3, p. 95-99, 1979. 
CRAVIOTO, A.; TELlO, A.; NAVARRO, A.; RUIZ, J.; VILLAFAN, H.; URIBE, F.; ESLAVA, C. Association of Escherichia coli Hep-2 adherence patterns with type and duration of diarrhea. Lancet, v. 337, p. 262-264, 1991.

DJORDJEVIC, S.P.; HORNITZKY, M.A.; BAILEY, M.; GILL, P.; VANSELOW, B.; WALKER, K.; BETTELHEIM, K.A. Virulence properties and serotypes of Shiga Toxinproducing Escherichia coli from healthy Australian slaughter-age sheep. J. Clin. Microbiol., v. 39, p. 2017-2021, 2001.

DONNENBERG, M.S.; KAPER, J.B.; FINLAY, B.B. Interactions between enteropathogenic Escherichia coli and host epithelial cells. Trends Microbiol., v. 5, p. 109-114, 1997.

EKLUND, M.; LEINO, K.; SIITONEM, A. Clinical E .coli strains carrying stx genes: stx variants and stx-positive virulence profiles. J. Clin. Microbiol., v. 40, p. 4585-4593, 2002.

ENDO, Y.; TSURUGI, K.; YUTSUDO, T.; YAKEDA, Y.; OGASAWARA, K.; IGARASHI, $\mathrm{K}$. The site of action of a verotoxin ( VT2 ) from Escherichia coli O157:H7 and of Shiga toxin on eukaryotic ribosomes: RNA N- glicosidade activity of the toxins. Eur. J. Biochem., v. 171, p. $45-50,1988$.

EWING W.H. Edwards \& Ewing's identification of Enterobacteriaceae. 4th ed. New York : Elsevier Science Publishers, 1999.

FEGAN, N.; DESMARCHELIER, P. Shiga toxin-producing Escherichia coli in sheep and pre-slaughter lambs in Eastern Australia. Lett. Appl. Microbiol., v. 28, p. 335-339, 1999.

FRIEDRICH, A.W.; BIELASZEWKA, M.; ZHANG, W.L.; PULZ, M.; KUCZIUS, T.; AMMON, A.; KARCH, H. Escherichia coli harboring Shiga toxin 2 gene variants: Frequency and association with clinical symptoms. J. Infect. Dis., v. 185, p. 74-84, 2002.

GALLAND, J.C.; HYATT, D.R.; CRUPPER, S.S.; ACHESON, D.W. Prevalence, antibiotic susceptibility, and diversity of Escherichia coli $\mathrm{O} 157: \mathrm{H} 7$ isolates from a longitudinal study of beef cattle feedlots. J. Clin. Microbiol., v. 67, p. 1619-1627, 2001.

GANNON, V.P; KING, R.K.; KIM, J.Y; THOMAS, E.J. Rapid and sensitive method for detection of Shiga like toxin-producing Escherichia coli in ground beef using the polymerase chain reaction. Appl. Environ, Microbiol., v. 58, p. 3809-3815, 1992.

GANNON, V.P; RASHED, N.; KING, R.K.; THOMAS, E.J. Detection and characterization of the eae gene of shiga-like toxin-producing Escherichia coli using polymerase chain reaction. J. Clin. Microbiol., v. 31, p. 1268-1274, 1993. 
GANSHEROFF, I. J.; O'BRIEN, A.D. Escherichia coli O157:H7 in beef cattle presented for slaughter in the U.S.: higher prevalence rates than previously estimated. Proc. Natl. Acad. Sci., v. 97, p. 2959-2961, 2000.

GAUTOM, R.K. Rapid pulsed-field gel electophoresis protocol for typing of Escherichia coli 0157:H7 and other Gram-negative organisms in 1 day. J. Clin. Microbiol., v. 35, p. 29772980, 1997.

GENTRY, M.K.; DARLYMPLE, J.M. Quantitative microtiter citotoxicity assay for Shigella toxin. J. Clin. Microbiol., v. 12, p. 361-366, 1980.

GIRÃO, D.M.; GIRÃO, V.B.; IRINO, K.; GOMES, T.A. Classifying Escherichia coli. Emerg. Infect. Dis., v. 12, p. 1297-1299, 2006.

GOLDWATER, P.N.; BETTELHEIM, K.A. Hemolytic uremic syndrome due to Shiga-like toxin producing Escherichia coli O48:H21 in South Australia. Emerg. Infect. Dis., v. 1, p. 132-133, 1995.

GOMES, T.A.T; VIEIRA, M.A.M.; ABE, C.M.; RODRIGUES, D.; GRIFFIN, P.M.; RAMOS, S.R.T.S. Adherence patterns and adherence-related DNA sequences in Escherichia coli isolates from children with and without diarrhea in São Paulo City, Brazil. J. Clin. Microbiol., v. 36, p. 3609-3613, 1998.

GOFFAUX, F.; CHINA, B.; MAINIL, J. Organization and in vitro expression of esp genes of the LEE (locus of enterocyte effacement) of bovine enteropathogenic and enterohemorrhagic Escherichia coli. Vet. Microbiol., v. 83, p. 275-286, 2001.

GRIFFIN, P.M.; TAUXE, R.V. The epidemiology of infections caused by Escherichia coli O157:H7, other enterohemorragic E. coli, and the associated hemolytic uremic syndrome. Epidemiol. Rev., v. 13, p. 60-98, 1991.

IGARASHI, T.; INATOMI, J.; WAKE, A.; TAKAMIZAWA, J.; KATAYAMA, H.; IWATA, T. Failure of pre-diarrheal antibiotics to prevente hemolytic uremic syndrome in serologically proven Escherichia coli O157:H7 gastrointestinal infection. J. Pediatr., v. 135, p. 768-769, 1999.

IKEDA, K.; IDA, O.; KIMOTO, K.; TAKATORIGE, T.; NAKANISHI, N.; TATARA, K. Effect of early fosfomycin treatment on prevention of hemolytic-uremic syndrome accompanying Escherichia coli O157:H7 infection. Clin. Nephrol., v. 52, p. 357-362, 1999.

JACEWICZ, M.; CLAUSEN, H.; NUDELMAN, E.; DONOHUE-ROLFE, A.; KEUSCH, G.T. Pathogenesis of Shigella diarrhea. XI. Isolation of Shigella toxin-binding glycolipid from rabbit jejunum and HeLa cells and its identification as globotriaosylceramide. J. Exp. Med., v. 163, p. 1391-1404, 1986. 
JACKSON, M.P.; NEILL, R.J.; O'BRIEN, A.D.; HOLMES, R.K.; NEWLAND, J.W. Nucleotide sequence analysis and comparison of the structural genes for Shiga-like toxin I and Shiga-like toxin II encoded by bacteriophages from Escherichia coli 933. FEMS Microbiol. Lett., v. 44, p. 109-114, 1987.

JAIN, S., CHAIN, J. Antibiotic resistance profiles and cell surface components os Salmonellae. J. Food Prot., v. 69, p. 1017-1023, 2006.

JENKINS, C., N.T. PERRY, T. CHEASTY, D.J. SHAW, G. FRANKEL, G. DOUGAN, G.J. GUNN, H.R. SMITH, A.W. PATON, J.C. PATON. Distribution of the saa gene in strains of Shiga toxin-producing Escherichia coli of human and bovine origins. J. Clin. Microbiol., v. 41, p.1775-1778, 2003.

JOHNSON, W.M.; LIOR, H.; BEZANSON, G.S. Cytotoxic Escherichia coli O157:H7 associated with haemorragic colitis in Canada. Lancet, v.1, p.76, 1983.

KANDEL, G.; DONOHUE-ROLFE, A.; DONOWITZ, M.; KEUSCH, G.T. Pathogenesis of Shigella diarrhea. XVI. Selective targeting of shiga toxin to villus cells of rabbit jejunum explains the effect of the toxin on intestinal electrolyte transport. J. Clin. Invest., v. 84, p. 1509-1517, 1989.

KAPER, J.B.; ELLIOT, S.; SPERANDIO, V.; PERNA, N.T.; MAYHEW, G.F.; BLATTNER, R.F. Attaching-and-effacing intestinal histopathology and locus of enterocyte effacement. In: KAPER, J.B.; O'BRIEN, A.D. (Ed.). Escherichia coli O157:H7 and other Shiga toxin-producing $\boldsymbol{E}$. coli strains. Washington, D.C.: ASM Press, 1998. p. 163-182.

KARAOLIS, D.K.; McDANIEL, T.K.; KAPER, J.B.; BOEDEKER, E.C. Cloning of the RDEC-1 locus of enterocyte effacement (LEE) and functional analysis of the phenotype on Hep-2 cell. Adv. Exp. Med. Biol., v. 412, p. 241-245, 1997.

KARMALI, M.A.; STEELE, B.T.; PETRIC, M.; LIM, C. Sporadic cases of haemolyticuremis syndrome associated with faecal cyto toxin and cytotoxin-producing Escherichia coli in stool. Lancet, p. 619-620, 1983.

KARMALI, M.A. Infectin by verocytotoxin-producing Escherichia coli. Clin. Microbiol. Rev., v. 2, p. 15-38, 1989.

KEENAN, K.P.; SHARPNACK, D.D.; COLLINS, H.; FORMAL, S.B.; O'BRIEN, A.D. Morphological evaluation of the effects of Shiga-toxin and E. coli Shiga-like toxin on the rabbit intestine. Am. J. Pathol., v. 125, p. 69-80, 1986. 
KENNY, B. Phosphorylation of tyrosine 474 of the enteropathogenic Escherichia coli (EPEC) Tir receptor molecule is essential for actin nucleating activity and is preceded by additional host modifications. Mol. Microbiol., v. 31, p.1229-1241, 1999.

KHACHATRYAN, A.R.; HANCOCK, D.D.; BESSER, T.E.; CALL, D.R. Role of calfadapted Escherichia coli in maintenance of antimicrobial drug resistance in dairy calves.

Appl. Environ. Microbiol., v. 70, p. 752-757, 2004.

KLEANTHOUS, H.; SMITH, H.R.; SCOTLAND, S.M.; GROSS, R.J.; ROWE, B.; TAYLOR, C.M.; MILFORD, D.V. Haemolytic uraemic syndrome in the British Isles, 19858: association with verocytotoxin producing Escherichia coli. part 2. Microbiological aspects. Arch. Dis. Child., v. 65, p. 722-727, 1990.

KOCH, C.; HERTWIG, S.; LURZ, R.; APPEL, B; BEUTIN, L. Isolation of a lysogenic bacteriophage carrying the stx1ox3 gene, which is closely associated with Shiga toxinproducing Escherichia coli stains from sheep and humans. J. Clin. Microbiol., v. 39, p. 39923998, 2001.

KONEMAN, E. W.; ALLEN, S. D.; JANDA, W. M.; SCHRECKENBERGER, P. C.; WINN, W. C. Diagnóstico Microbiológico. 5. ed. Washington: MEDSI, 2001.

KONOWALCHUK, J.; SPEIRS, J.I.; STAVRIC.S. Vero response to a cytotoxin of Escherichia coli. Infect. Immun., v. 18, p. 775-779, 1977.

KUDVA, I.T.; HATFIELD, P.G.; HODVE, C.J. Characterization of Escherichia coli O157:H7 and other Shiga toxin-producing E. coli serotypes isolated from sheep. J. Clin. Microbiol., v. 35, p. 892-899, 1997.

LEUNG, P.H.; PEIRIS, J.S.; NG, W.W.; ROBINS-BROWNE, R.M.; BETTELHEIM, K.A.; YAM, W.C. A new discovered verotoxin variant, VT2g, produced by bovine verocytotoxigenic Escherichia coli. Appl. Environ. Microbiol., v. 96, p. 7549-7553, 2003.

LEVINE, M.M.; XU, J.; KAPER, J.B.; LIOR, H.; PRADO, V.; TALL, B.; NATARRO, J.; KARCH, H.; WACHMUTH, K. A DNA probe to identify enterohemorragic Escherichia coli of $\mathrm{O} 157: \mathrm{H} 7$ and other serotypes that cause hemorrhagic colitis and hemolytic uremic syndrome. J. Infect. Dis., v. 156, p. 175-182, 1987.

LICENCE, K.; OATES, K.R.; SYNGE, B.A.; REID, T.M. An outbreak of E.coli O157 infection with evidence of spread from animals to man through contamination of a private water supply. Epidemiol. Infect., v. 126, p. 135-138, 2001. 
LINDGREN, S.W.; MELTON, A.R.; O'BRIAN, A.D. Virulence of enterohemorrhagic Escherichia coli $\mathrm{O} 91: \mathrm{H} 21$ clinical isolates in an orally infected mouse model. Infect. Immun.,v. 61, p. 3832-3842, 1993.

LOUIE, M.; READ, S.; LOUIE, S.; ZIEBELL, K.; RAHN, K.; BORCZYK, A.; LIOR, H. Molecular typing methods to investigate transmission of Escherichia coli O157:H7 from cattle to humans. Epidemiol. Infect., v. 123, p. 17-24, 1999.

MACHADO, J.; GRIMONT, F.; GRIMONT, P.A. Identification of E. coli flagellar types by restriction of the amplified fliC genes. Res. Microbiol., v. 151, p. 535-546, 2000.

MAINIL, J.G.; JACQUEMIN, E.R.; KAECKENBEECK, A.E.; POHL, P.H. Association between the effacing (eae) gene and the Shiga-like toxin-encoding genes in Escherichia coli isolates from cattle. Am. J. Vet. Res., v. 54, p. 1064-1068, 1993.

MAULE, A. Survival of verocytotoxigenic Escherichia coli O157:H7 in soil, water and on surfaces. Symp. Ser. Soc. Appl. Microbiol., v.29, p. 71S-78S, 2000.

McDANIEL, T.K.; JARVIS, K.G.; DONNENBERG, M.S.; KAPER, J.B. A genetic locus of enterocyte effacement conserved among diverse enterobacterial pathogens. Proc. Natl. Acad. Sci. USA, v. 92, p. 1664-1668, 1995.

MELTON-CELSA, A.R.; DARNELL, S.C.; O'BRIEN, A.D. Activation of Shiga-like toxins by mouse and humans intestinal mucus correlates with virulence of enterohemorrhagic Escherichia coli $\mathrm{O} 91: \mathrm{H} 21$ isolates in orally infected, streptomycin-treated mice. Infect. Immun., v. 64, p. 1569-1576, 1996.

MELTON-CELSA, A.R.; O'BRIEN, A.D. Structure, biology, and relative toxicity of Shiga toxin family members for cells and animals, In: KAPER, J.B.; O'BRIEN, A.D. (Ed.). Escherichia coli 0157:H7 and other Shiga toxin-producing $E$. coli strains. Washington, D.C.: ASM Press, 1998. p. 121-128.

MENG, J.; DOYLE, M.P. Microbiology of Shiga Toxin-producing Escherichia coli in foods. In: KAPER, J.B.; O'BRIEN, A.D. (Ed.). Escherichia coli 0157:H7 and other Shiga toxinproducing E. coli strains. Washington, D.C.: ASM Press, 1998. p. 92-108.

MICHINO, H.; ARAKI, K.; MINAMI, S.; TAKAYA, S.; SAKAI, N.; MIYAZAKI, M.; ONO, A; YANAGAWA, H. Massive outbreak of Escherichia coli O157:H7 infection in schoolchildren in Sakai City, Japan, associated with consumption of white radish sprouts, Am. J. Epidemiol., v. 150, p.797-803, 1999. 
MOCE-LLIVINA, L.; MUNIESA, M.; PIMENTA-VALE, H.; LUCENA, F.; JOFRE, J. Survival of bacterial indicator species and bacteriophages alter thermal treatment of sludge and sewage. Appl. Environ. Microbiol., v. 69, p. 1452-1456, 2003.

MOHAMMAD, A.; PEIRIS, J.S.M.; WIJEWANTA, E.A.; MAHALINGAM, S.; GUNASEKARA, G. Role of cerocytotoxigenic Escherichia coli in cattle and buffalo calf diarrhoea. FEMS Microbiol. Lett., v. 26, p. 281-183, 1985.

MORA, A.;BLANCO, J.E.; BLANCO, M.; ALONSO, M.P.; DHABI, G.; ECHEITA, A.; GONZÁLEZ, E.A.; BERNARDEZ, M.I.; BLANCO, J. Antimicrobial resistance of Shiga toxin (verotoxin)-producing Escherichia coli $\mathrm{O} 157: \mathrm{H} 7$ and non- O157:H7 strains isolated from humans, cattle, sheep and food in Spain. Res. Microbiol., v.156, p. 793-806, 2005.

NATARO, J.P.; KAPER, J.B. Diarrheagenic Escherichia coli. Clin. Microbiol. Reviews, v.11, p. 142-201, 1998.

O'BRIEN, A.D.; LA VECK, G.D.; THOMPSON, M.R.; FORMAL, S.B. Productions of Shigella dysenteriae 1-like cytotoxin by Escherichia coli. J. Infect. Dis., v. 146, p. 763-769, 1982.

O'BRIEN, A.D.; LIVELY, T.A.; CHEN, M.E.; ROTHMAN, S.W.; FORMAL, S.B. Escherichia coli $\mathrm{O} 157$ strain associated with hemorrhagic colitis in the United States produce a Shigella dysenteriae 1 (Shiga ) like toxin. Lancet, v.1, p. 702, 1983.

O’BRIEN, A.D.; HOLMES, R.K. Shiga and Shiga-like toxins. Microbiol. Rev., v. 51, p. 206$220,1987$.

O'BRIEN, A.D.;TESH, V.; DONOHUE-ROLFE, A. Shiga toxin: biochemistry, genetics, mode of action, and role in pathogenesis. Curr. Top. Microbiol. Immunol., v. 180, p. 65-94, 1992.

OGDEN, I.D; MaCRAE, M.; STRACHAN, N.J.C. Concentration and prevalence of Escherichia coli O 157 in sheep faeces at pasture in Scotland. J. Appl. Microbiol., v. 98, p. 646-651, 2005.

OMISAKIN, F; MaCRAE, M.; OGDEN, I.D.; STRACHAN, N.J.C. Concentration and prevalence of Escherichia coli $\mathrm{O} 157$ in cattle feces at slaughter. Appl. Environm. Microbiol. , v. 69 , p. $2444-2447,2003$

ORDEN, J.A.; CORTES, C.; RUIZ-SANTA-QUITERIA, J.A.; MARTINEZ, S.; DE LA FUENTE, R. Detection of the saa gene in Verotoxin-producing Escherichia coli from ruminants. J. Vet. Diagn. Invest., v. 17, p. 65-67, 2005. 
OSWALD, E.; SCHIMIDT, H.; MORABITO, S.; KARCH, H.; MARCHÈS, O.; CAPRIOLI, A. Typing of intimin genes in human and animal enterohemorrhagic and enteropathogenic Escherichia coli: characterization of a new intimin variant. Infect. Immun., v. 68, p.64-71, 2000 .

PATON, A.W.; PATON, J.C.; GOLDWATER, P.N.; HEUZENROEDER, M.W.; MANNING, P.A. Sequence of a variant Shiga-like toxin type-I operon of Escherichia coli O111:H-. Gene, v. 129, p.87-92, 1993.

PATON, A.W.; BEUTIN, L.; PATON, J.C. Heterogeneity of the amino-acid sequences of Escherichia coli Shiga-like toxin type I operons. Gene, v. 153, p. 71-74,1995.

PATON, A.W.; MANNING, P.A.; WOODROW, M.C.; PATON, J.C. Translocated intimin receptors (Tir) of Shiga-toxigenic Escherichia coli isolates belonging to serogroups O26, O111, and $\mathrm{O} 157$ react with sera from patients with hemolytic-uremic syndrome and exhibit marked sequence heterogeneity. Infect. Immun., v. 66, p. 5580-5586, 1998.

PATON, A.W.; WOODROW, M.C.; DOYLE, R.M.; LANSER, J.A.; PATON, J.C. Molecular characterization of a shiga toxigenic Escherichia coli O113:H21 strain lacking eae responsible for a cluster of cases of Hemolytic-uremic syndrome. J. Clin. Microbiol., v. 37, p. 3357-3361, 1999.

PATON, A.W.; SRIMANOTE, P.; WOODROW, M.C.; PATON, J.C. Characterization of Saa, a novel autoagglutinating adhesin produced by locus of enterocyte effacement-negative Shiga-toxigenic Escherichia coli strains that are virulent for humans. Infect. Immun., v. 69, p. 6999-7009, 2001.

PHILLIPS, A.D.; FRANKEL, G. Intimin-mediated tissue specificity in enteropathogenic Escherichia coli interaction with human intestinal organ cultures. J. Infect. Dis., v. 181, p. 1496-1500, 2000.

PIERARD, D.; MUYLDERMANS, G.; MORIAU, L.; STEVENS, D.; LAUWERS, S. Identification of new Verocytotoxin type 2 variant B-subunit genes in human and animal Escherichia coli isolates. J. Clin. Microbiol., v. 36, p. 3317-3322, 1998.

POLLARD, D.R.; JOHNSON, W.N.; LIOR, H.; TYLER, S.D.; ROZEE, K.R. Differentiation of Shiga toxin and vero cytotoxin type I genes by polymerase chain reaction. J. Infect. Dis., v.162, p. 1195-1198, 1990.

PRESTON, M.A.; JOHNSON, W.; KHAKHIRIA, R.; BORCZYK, A. Epidemiologic subtyping of Escherichia coli serogroup O157:H7 strains isolated in Ontario by phage typing and pulsed field gel electrophoresis. J. Clin. Microbiol., v. 38, p. 2366-2368, 2000. 
RAMACHANDRAN, V., HORNITZKY, M.A., BETTELHEIM, K.A., WALKER, M.J. AND DJORDJEVIC, S.P. The common ovine Shiga toxin 2-containing Escherichia coli serotypes and human isolates of the same serotypes possess a Stx2d toxin type. J. Clin. Microbiol., v. 39, p. 1932-1937, 2001.

RAMACHANDRAN, V.; BRETT, K.; HORNITZKY, M.A.; DOWTON, M.; BETTELHEIM, K.A.; WALKER, M.J.; DJORDJERVIC, S.P. Distribution of intimin subtypes among Escherichia coli isolates from ruminant and human sources. J. Clin. Microbiol., v.41, p. 5022-5032, 2003.

RASHID, R.A.; TABATA, T.A.; OATLEY, M.J.; BESSER, T.E.; TARR, P.I.; MOSELEY, S.L. Expression of putative virulence factors of Escherichia coli O157:H7 differs in bovine and human infections. Infect. Immun., v. 74, p. 4142-4148, 2006.

REY, J.; BLANCO, J.E.; BLANCO, M.; MORA, A.; DAHBI, G.; ALONSO, J.M.; HERMOSO, M.; HERMOSO, J.; ALONSO, M.P; USERA, M.A.; GONZALEZ, E.A.; BERNARDEZ, M.I.; BLANCO, J. Serotypes, phage types and virulence genes of shigaproducing Escherichia coli isolated from sheep in Spain. Vet. Microbiol., v. 94, p. 47-56, 2003.

RILEY, L.W.; REMIS, R.S.; HELGERSON, S.D.;MCGEE, H.B.; WELLS, J.G.; DAVIS, B.R. Hemorrhagic colitis associated with a rare E.coli serotype. New England J. Med., v. 308, p. 681-685, 1983.

RODRIGUES, J.; SCALETSKY, I.C.; CAMPOS, L.C.; GOMES, T.A.; WHITTAM, T.S.; TRABULSI, L.R. Clonal structure and virulence factors in strains of Escherichia coli of the classic serogroup O55. Infect. Immun., v. 64, p. 2680-2686, 1996.

RUSSMANN, H.; KOTHE, E.; SCHMIDT, H.; FRANKE, S.; HARMSEN, D.; CAPRIOLI, A.; KARCH, H. Genotyping of Shiga-like toxin genes in non-O157 Escherichia coli strains associated with haemolytic uremic syndrome. J. Med. Microbiol., v. 42, p. 404-410, 1995.

SALYERS, A.A.; WHITT, D.D. Bacterial pathogenesis, a molecular approach. United States: ASM Press, 1994. v. 16, p. 190-204.

SCALETSKY, I.C; SILVA, M.L.; TRABULSI, L.R. Distinctive patterns of adherence of enteropathogenic Escherichia coli to HeLa cells. Infect. Immun., v. 45, p. 534-536, 1984

SCALETSKY, I.C.; PEDROSO, M.Z.; MORAIS, M.B.; CARVALHO, R.L.; SILVA, R.M.; FABBRICOTTI, S.H.; FAGUNDES-NETO, U. Association of patterns of Escherichia coli adherence to HEp-2 cells with acute and persistent diarrea. Arq. Gastroenterol., v. 36, p. 5460, 1996. 
SCALETSKY, I.C.; PEDROSO, M.Z.; OLIVA, C.A.; MORAIS, M.B.; CARVALHO, R.L.; SILVA, R.M.; FAGUNDES-NETO, U. A localized adherence-like pattern as a second pattern of adherence of classic enteropathogenic Escherichia coli to HEp-2 cells that is associated with infantile diarrhea. Infect. Immun., v. 67, p. 3410-5, 1999.

SCHMIDT, H.; MONTAG, M.; BOCKEMUHL, J.; HEESEMANN, J.; KARCH, H. Shiga like toxin II-related cytotoxins in Citrobacter freundii strains from humans and beef samples. Infect. Immun., v. 61, p. 534-543, 1993.

SCHMIDT, H.; KERNBACH, C.; KARCH, H. Analysis of the EHEC hly operon and its location in the physical map of the large plasmid of enterohaemorrhagic Escherichia coli O157:H7. Microbiology, v. 142, p. 907-914, 1994.

SCHMIDT, H.; BEUTIN, L.; KARCH, H. Molecular analyses of the plasmid-encoded hemolysin of Escherichia coli O157:H7 strain EDL933. Infect. Immun., v. 63, p. 1055-1061, 1995.

SCHMIDT, H.; SCHEEF, J.; MORABITO, S.; CAPRIOLI, A.; WIELER, L.H.; KARCH, H. A new Shiga toxin 2 variant (Stx2f) from Escherichia coli isolated from pigeons. Appl. Environm. Microbiol., v. 66, p. 1205-1208, 2000.

SCHROEDER, M.C.; ZHAO, C.; DEBROY, C.; TORCOLINI, J.; ZHAO, S.; WHITE, D.G.; WAGNER, D.D.; MC DERMOTT, P.F. Antimicrobial resistance of Escherichia coli O157 isolated from humans, cattle, swine and food. Appl. Environ. Microbiol., v. 68, p. 576-581, 2002.

SIDJABAT TAMBUNAN, H.; BENSINK, J.C. Verotoxin-producing Escherichia coli from the faeces of sheep, calves and pigs. Aust. Vet. J., v. 75, p. 292-293, 1997.

SOUZA, R.L.; NISHIMURA, L.S.; GUTH, B.E.C. Uncommon Shiga toxin-producing E. coli serotype O165:HNM as cause of hemolytic uremic syndrome in São Paulo, Brazil. Diag. Microbiol. Infect. Dis., v. 59, p. 223-225, 2007.

STRACHAN, N.J.; FENLON, D.R.; ODGEN, I.D. Modeling the vector pathway and infection of humans in an environmental outbreak of Escherichia coli O157:H7. FEMS Microbiol. Lett., v. 203, p. 69-73, 2001.

TARR, C.L.; WHITTAM, T.S. Molecular evolution of the intimin gene in O111 clones of pathogenic Escherichia coli. J. Bacteriol., v. 184, p. 479-487, 2002.

TESH, V.L.; O'BRIEN, A.D. The pathogenic mechanisms of Shiga toxin and Shiga-like toxins. Mol. Microbiol., v. 5, p. 1817-1822, 1991. 
TOMA, C.; MARTINEZ ESPINOSA, E.; SONG, T.; MILIWEBSKY, E.; CHINEN, I.; IYODA, S.; IWIANAGA, M.; RIVAS, M. Distribution of putative adhesins in different seropathotypes of Shiga toxin-producing Escherichia coli. J. Clin. Microbiol., v. 42, p. 49374946, 2004.

TRABULSI, L.R.; ALTERTHUM, F. Microbiologia. 4 ed. São Paulo: Atheneu, 2005.

TRABULSI, L.R.; KELLER, R.; GOMES, T.A.T. Typical and atypical enteropathogenic Escherichia coli. Emerg. Infect. Dis., v. 8, p. 508-513, 2002.

TRABULSI, L.R. Microbiologia. 3 ed. São Paulo: Atheneu, 1999.

TYLER, S.D.; JOHNSON, W.; LIOR, H.; WANGG.; ROSEE, K.R. Identification of verotoxin type 2 variant $\mathrm{B}$ subunit genes in $E$. coli by the polymerase chain reaction and restriction fragment lenth polymorphism analysis. J. Clin. Microbiol., v. 29, p. 1339-1343, 1991.

URDAHL, A.M.; ALVSEIKE, O.; SKJERVE, E.; WASTESON, Y. Shiga toxin genes (stx) in Norwegian sheep herds. Epidemiol.Infect., v. 127, p. 129-134, 2001.

VARMA, J.K.; GREENE, K.D.; RELLER. M.E.; DELONG, S.M.; TROTTIER, J.; NOWICKI, S.F.; DIORIO, M.; KOCH, E.M. An outbreak of Escherichia coli O157 infection following exposure to a contaminated building. J. Am. Med. Assoc., v. 290, p. 2709-2712, 2003.

VAZ, T.M.; IRINI, K.; KATO, M.A.; DIAS, A.M.; GOMES, T.A.; MEDEIROS, M.I.; ROCHA, M.M.; GUTH, B.E. Virulence properties and characteristics os Shiga toxinproducing Escherichia coli in São Paulo, Brazil, from 1976 through 1999. J. Clin. Microbiol., v. 42, p. 903-905, 2004.

VERNOZY-ROZAND, C.; MONTET, M.P.; BERTIN, Y.; TRABLY, F.; GIRARDEAU, J.P.; MARTIN, C.; LIVRELLI, V.L.; BEUTIN, L. Serotyping, stx2 subtyping, and characterization of the lócus of enterocyte effacement island of Shiga toxin-producing Escherichia coli and E. coli $\mathrm{O} 157: \mathrm{H} 7$ strains isolated from the environment in France. Appl. Environ. Microbiol., v. 70, p. 2556-2559, 2004.

VETTORATO, M.P.; LEOMIL, L.; GUTH, B.E.C.; IRINO, K.; PESTANA DE CASTRO, A.F. Properties of Shiga toxin-producing Escherichia coli (STEC) isolates from sheep in the State of São Paulo, Brazil. Vet. Microbiol., v. 95, p. 103-109, 2003.

VIEIRA, M.A.M.; ANDRADE, R.C.; TRABULSI, L.R.; ROSA, A.C.P.; DIAS, A.M.G.; RAMOS, S.R.T.S.; FRANKEL, G.; GOMES, T.A.T. Phenotypic and genotypic characterization of Escherichia coli strains of non-enteropathogenic E. coli serogroups that 
carry eae and lack the EPEC adherence factor and shiga toxin DNA probe sequences. $\mathbf{J}$. Infect. Dis., v.183, p.762-772, 2001.

WALES, A.D.; PEARSON, G.R.; BEST, A.; COOKSON, A.L.; LA RAGIONE, R.M.; ROE, J.M.; HAYES, C.M.; WOODWART, M.J. Naturally acquired attaching and effacing Escherichia coli in sheep. Res. Vet. Sci., v. 78, p. 109-115. 2005.

WANG, G.; ZHAO, T.; DOYLE, M.P. Fate of enterohemorrhagic Escherichia coli O157:H7 in bovine feces. Appl. Environ. Microbiol., v. 62, p. 2567-2570, 1996.

WANI, S.A.; SAMANTA, I.; MUNSHI, Z.H.; BHAT, M.A.; NISHIKAWA, Y. Shiga toxinproducing Escherichia coli and Enteropathogenic Escherichia coli in healthy goats in India: occurrence and virulence properties. J. Appl. Microbiol., v. 100, p. 108-113, 2006.

WANI, S.A.; BHAT, M.A.; SAMANTA, I.; NISHIKAWA, Y.; BUCHH, A.S. Isolation and characterization of Shiga toxin-producing Escherichia coli (STEC) and Enteropathogenic Escherichia coli (EPEC) from calves and lambs with diarrhea in India. Lett. Appl. Microbiol., v. 37, p. 121-126, 2003.

WHIPP, S.C.; RASMUSSEN, M.A.; CRAY Jr, W.C. Animals as a source of Escherichia coli pathogenic for human beings. J. Am. Med. Assoc., v. 204, p.1168-1175, 1994.

WIELER, L.H.; SCHWANITZ, A.; VIELER, E.; BUSSE, B.; STEINRÜCK, H.; KAPER, J.B.; BALJER, G. Virulence properties of Shiga toxin-producing Escherichia coli ( STEC ) strains of serogroup O118, a major group of STEC pathogens in calves. Infect. Immun., v. 36, p. 1604-1607, 1998.

WILLSHAW, G.A.; SMITH, H.R.; CHEASTY, T.; WALL, O.G.; ROWE, B. Verocytotoxinproducing Escherichia coli O157:H7 outbreaks in England and Wales, 1995: Phenotypic methods and genotypic subtyping. Emerg. Infect. Dis., v.3, p. 561-565, 1997.

WONG, C.S.; JELACIE, S.; HABEEB, R.L.; WATKINS, S.L.; TARR, P.I. The risk of Hemolytic uremic syndrome after antibiotic treatment of Escherichia coli O157:H7 infections. New Engl. J. Med., v. 342, p. 1930-1936, 2000.

YOH, M.; HONDA, T. The stimulating effects of fosfomycin, an antibiotic in common use in Japan, on the production/release of verotoxin-1 from enterohaemorrhagic Escherichia coli O157:H7 in vitro. Epidemiol. Infect., v, 119, p. 101-103, 1997.

YOU, J.; MOON, B.; OH, I.; BAEK, B.; LI, L.; KIM, B.; STEIN, B.D.; LEE, J.H. Antimicrobial resistance of Escherichia coli $\mathrm{O} 157$ isolated from cattle in Corea. J. Food. Microbiol., v. 106, p. 74-78, 2005. 
ZHANG, X.; MC DANIEL, A.D.; WOLF, L.E.; KEUSCH, G.T.; WALDOR, M.K.; ACHESON, D.W. Quinolone antibiotics induce Shiga toxin-encoding bacteriophages, toxin production, and dead in mice. J. Infect. Dis., v.181, p. 664-670, 2000.

ZHANG, W.L.; KÖHLER, B.; OSWALD, E.; BEUTIN, L.; KARCH, H.; MORABITO, S.; CAPRIOLI, A.; SUERBAUM, S.; SCHMIDT, H. Genetic diversity of intimin genes of attaching and effacing Escherichia coli strains. J. Clin. Microbiol., v. 40, p. 4486-4492, 2002.

ZSCHOCK, M.; HAMANN, H.P.; KLOPPERT, B.; WOLTER, W. Shiga-toxin-producing Escherichia coli in feaces of healthy dairy cows, sheep and goats; prevalence and virulence properties. Lett. Appl. Microbiol., v.31, p. 203-208, 2000. 